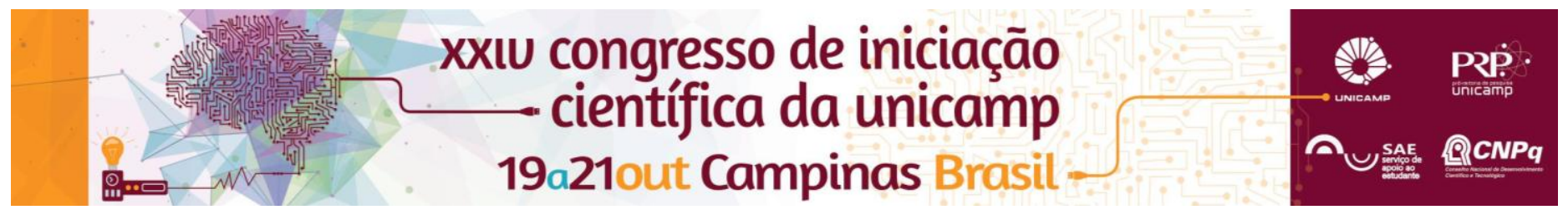

\title{
Avaliação do Sistema Renina-Angiotensina em camundongos portadores de Anemia Falciforme
}

\section{Pamela Lara de Brito*, Nicola Conran Zorzetto}

\section{Resumo}

As manifestações clinicas da Anemia Falciforme são decorrentes do processo vaso-oclusivo. Nos rins, a isquemia, necrose tubular e hipertrofia glomerular englobam as principais complicações devido a falcização do eritrócito na vasculatura renal. Investigamos a hipótese de que estas alterações hemodinâmicas podem levar a formação de Angiotensina II que atua na vasoconstrição e alteração da pressão arterial.

Palavras-chave: Anemia Falciforme, renina-angiotensina, pressão arterial.

\section{Introdução}

A anemia falciforme (AF) é uma doença genética causada pela substituição de um ácido glutâmico por uma valina na posição 6 da beta-globina, gerando a hemoglobina $\mathrm{S}(\mathrm{HbS})$. Em condições de hipóxia a HbS se polimeriza tornando a hemácia propensa à falcização, evento que pode levar a oclusão da microvasculatura com conseqüente complicações clínicas ${ }^{1}$. Os rins são órgãos essenciais para manutenção da homeostasia e participação na modulação da pressão arterial sistêmica (PAS). A medula renal é um local onde a $\mathrm{HbS}$ tem maior propensão à polimerização podendo gerar a isquemia renal $^{2}$. Esta alteração no fluxo sanguíneo pode levar a ativação do Sistema Renina-Angiotensina (SRA), que tem como produto final a angiotensina II (Ang II) com capacidade vasoconstritora e ação inflamatória ${ }^{3}$. Neste estudo buscamos avaliar as alterações no SRA em um modelo animal de AF.

\section{Resultados e Discussão}

Foi analisada a PAS de camundongos da linhagem C57BL6 transplantados AF e C57BL6 (controle CON) e camundongos C57BL6 selvagens (WT). O valore obtido para o grupo CON foi semelhante ao WT, enquanto que no AF foi significativamente menor comparado ao WT, entretanto deve-se considerar a perda significativa do número amostral devido a morte precoce destes camundongos AF.

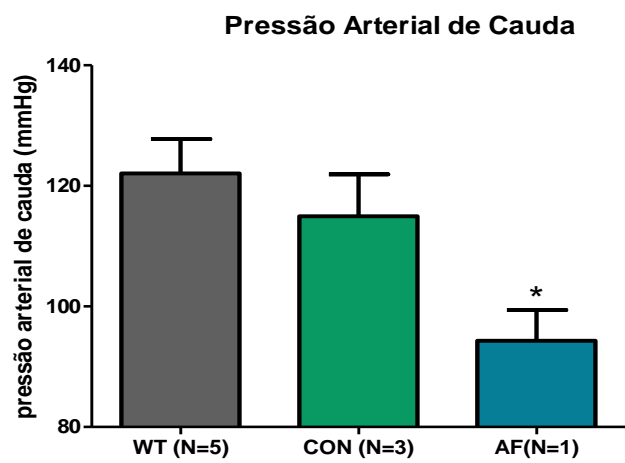

Figura 1. Valores de PAS da cauda dos animais dos grupos WT $(122,1 \pm 5,8 \mathrm{mmHg})$, CON $(114,9 \pm 7,0 \mathrm{mmHg})$ e $\mathrm{AF}(94,3$ $\left.\pm 5,1 \mathrm{mmHg},{ }^{\star} \mathrm{P}<0,05\right)$, Kruskal-wallis, pós- teste de Dunn.

O SRA participa da manutenção da PAS pela redução do calibre dos vasos, mediado pela Ang II e indução da produção de aldosterona levando ao aumento da volemia e da PAS ${ }^{4}$. Ainda não há estudos que correlacione o SRA com PAS de pacientes AF, entretanto sabe-se que estes apresentam menor incidência a hipertensão e redução da PA em relação a indivíduos normais ${ }^{5}$. Amostras de urina de 24 horas foram analisadas por tiras reagentes para glicosúria, hematúria, proteinúria e $\mathrm{pH}$, entretanto não houve alterações nesses parâmetros e diferença significativa para diurese. A presença de sangue e proteínas na urina pode ser causada pela necrose tubular gerada pela isquemia renal ${ }^{2}$. Para verificar a expressão de proteínas do SRA nos rins foram padronizadas as concentrações dos anticorpos para imunofluorescência em cortes de $10 \mu \mathrm{m}$ de rins de camundongos WT. Assim como constatado na literatura, os elementos do SRA estão presentes nos rins em diferentes localizações ${ }^{6}$. Nos túbulos renais, encontramos a expressão de nefrina, enzima conversora de angiotensina (ECA), receptores do tipo 2 de angiotensina II $\left(\mathrm{AT}_{2}\right)$ e Ang II, enquanto que a renina também estava presente na região do glomérulo. Os macrófagos não são comumente encontrados na ausência de inflamação, mas estudos mostram que elevação dos níveis de Ang II induz a ativação dessas células ${ }^{7}$. Análise da imunomarcação do tecido mostrou a presença rara de macrófagos maduros em túbulos renais.

\section{Conclusões}

Neste estudo é investigado se o SRA está alterado em animais AF e alterações morfológicas que caracterizem a doença renal. Os resultados aqui apresentados são preliminares, entretanto a metodologia apresentada foi validada e nos permitirá dar continuidade com os próximos grupos experimentais.

\section{Agradecimentos Agencia financiadora: FAPESP.}

\footnotetext{
${ }^{1}$ Steinberg, M. H. Management of sickle cell disease. N. Engl. J. Med. 1999, 340, 10-30.

${ }^{2}$ Ataga, K. I.; Derebail, V. K.; Archer, D. R. The glomerulopathy of sickle cell disease. Am. J. Hematol. 2014, 89(9), 907-14

${ }^{3}$ Cat, A. N. D.; Touyz, R. M. A new look at the rennin-angiotensin system Focusing on the vascular system. Peptides. 2011, 32, 2141-2150

${ }^{4}$ Ferrario, C. M.; Strawn, W. B. Role of the renin-angiotensin-aldosterone system and proinflammatory mediators in cardiovascular disease. Am. J Cardiol. 2006, 98, 121-128.

${ }^{5}$ Johnson, C. S. Arterial blood pressure anhyperviscosity in sicle cell disease. Hematol.Oncol. N. Am. 2005, 19, 827-837.

${ }^{6}$ Kobori, H. et al. The intrarenal renin-angiotensin system: from physiology to the pathobiology of hypertension and kidney disease. Pharmacol. Rev. 2007, 59, 251-287.

${ }^{7}$ Guo, F. et al. Role of angiotensin II type 1 receptor in angiotensin II-induced cytokine production in macrophages. J Interf. Cytok. Res. 2011, 31, 351-361.
} 